\title{
Analysing the Adoption of Lean Production in Remanufacturing Industry
}

\author{
Anjar Priyono ${ }^{1}$ iD, Fazli Idris ${ }^{2}$ iD \\ ${ }^{1}$ Universitas Islam Indonesia (Indonesia) \\ ${ }^{2}$ Universiti Kebangsaan Malaysia (Malaysia) \\ anjar.priyono@uii.ac.id,fąli@ukm.edu.my
}

Received: March 2018

Accepted: September 2018

\begin{abstract}
:
Purpose: This paper aims to analyse the challenges of lean manufacturing implementation in the remanufacturing industry. The research was undertaken in three types of remanufacturing company, torque converter, gearbox, and jet engine remanufacturers. This paper describes the characteristics of remanufacturing companies and compares them with the best practice company adopting lean manufacturing best practice: Toyota Motor Company. Through a comparison of the characteristics of the manufacturing environment, macro, and external condition, the challenges of adopting lean manufacturing are identified.
\end{abstract}

Design/methodology/approach: This study utilised a case study method to analyse qualitative data collected from interviews, observations, and focus group discussions. Although case studies are typically used in inductive research, this study followed a deductive approach.

Findings: The analysis demonstrated that remanufacturing companies experience challenges due to contextual differences to the benchmark company. The research found that there are some practices that are embedded in remanufacturing companies, but that the companies do not realise that these are lean manufacturing practices. On the other hand, there are a number of external factors that are beyond the remanufacturers' control that hinder the adoption of lean manufacturing. In addition, the aftermarket business of remanufacturers has resulted in a number of distinctive macro condition characteristics that make the adoption of lean manufacturing more complex.

Practical implications: Successfully addressing barriers to lean manufacturing adoption might enhance the performance of remanufacturing process. This is because the business of remanufacturing is not value creation, but capturing value from used products.

Originality/value: This paper contributes to existing literature examining lean production in remanufacturing companies. It is novel in the sense that it is the first study examining lean production in the remanufacturing industry from organisational and managerial perspectives.

Keywords: lean manufacturing, Toyota Production System, remanufacturing industry, aftermarket industry, sustainability

\section{To cite this article:}

Priyono, A., \& Idris, F. (2018). Analysing the adoption of lean production in remanufacturing industry. Journal of Industrial Engineering and Management, 11(4), 697-714. https://doi.org/10.3926/jiem.2614 


\section{Introduction}

Remanufacturing is a process in which used products, referred to as "cores", are reprocessed into like-new products. During the remanufacturing process, cores undergo a series of processes including inspection, disassembly, testing, reassembly, and a final check to ensure that the final products meet the remanufactured product specifications (Ijomah, 2009).

The remanufacturing process differs according to the products, with each possessing a different return flow, characteristics, yield, and potential value of recovered components (Ferrer, 2003). Transferring lean manufacturing, which was developed in automotive industry, to remanufacturing industry could be complex process due to stickiness issues. Danese, Romano and Boscari (2017) examined how stickiness issues hinder lean implementation. Stickiness was defined as the extent to which companies stick to current manufacturing process and high resistance to change.

Organisations in certain types of industry experience difficulties adopting lean and consequently they adopt some relevant lean methods, and only in specific situations to improve their operations. Some examples of the industry types include upstream continuous processing industries and complex transaction processes. Although companies have attempted to adopt lean tools as much as possible, there are some tools that are not compatible with specific situations. It is thus very rare for companies to be completely lean, which is known as operational excellence. In practice, partial implementation is more achievable, and does not involve making fundamental changes to organisational structure (Bamford, Forrester, Dehe \& Leese, 2015).

Remanufacturing is strongly associated with sustainable manufacturing practices. Despite the differences between manufacturing and remanufacturing industry, the practice that is useful for adopting lean, most likely will be worthwhile to support sustainability practices in remanufacturing companies. Also, both concepts use identical ways during implementation: using problem solving, team working, production inspection and training (Piercy \& Rich, 2015). A number of lean concepts were also found in sustainability context, such as employee engagement, safety environment, waste reduction, recycling, and community engagement. Further, Piercy and Rich (2015) found that it is better for companies to implement lean manufacturing first before adopting sustainability. Lean provides foundation for sustainability. They also suggest that there is no trade off between lean and sustainability; however, there is not any evidence that when one of them is implemented, it will automatically lead to progression of the other.

Previous studies on the topic of lean in remanufacturing industry have mostly addressed operational-level. For instance, Hunter and Black (2007) analysed the use of lean manufacturing in mobile phone remanufacturing. Their detailed case study focused on how to design a shop floor to support the remanufacturing process. In another study, Ostlin and Ekholm (2007) investigated the process of remanufacturing toner cartridge. Both studies focused on the operational level. The analysis in both studies stressed that lean is not only about reducing waste, in other words an operational issue, it is a broad concept requiring a strategic approach (Liker \& Meier, 2006).

In addition, lean implementation involves not only hard factors - e.g. product design, use of automation, technology support - but also soft factors, such as organisational design, management support, organisational culture, and collaborative decision-making, among others (Liker \& Meier, 2006). To support end-of-life strategies, the organisation should react to the way the products are designed. Successful end-of-life strategies cannot rely on product design; rather, they should consider how the organisation and supply chain could support product recovery (Gehin, Zwolinski \& Brissaud, 2008).

For this reason, themes related to strategic factors, such as the type of remanufacturer (Lind, Olsson \& Sundin, 2014; Lund, 1984), relationships with core suppliers (Lind et al., 2014; Östlin, Sundin \& Björkman, 2008; Saavedra, Barquet, Rozenfeld, Forcellini \& Ometto, 2013), and product knowledge transfer (Gehin et al., 2008; Inderfurth, Vogelgesang \& Langella, 2015; Saavedra et al., 2013) should also be addressed. Similarly, issues relating to process choices, such as the use of automation (Franke, Basdere, Ciupek \& Seliger, 2006; Sundin, Elo \& Mien-Lee, 2012), and employee skills (Behdad, Williams \& Thurston, 2012; Ferrer \& Whybark, 2000) must also be incorporated. Those are just a few examples of issues that should be incorporated into a comprehensive study of lean 
remanufacturing. Lean implementation is one issue that seems not to have been addressed from a strategic perspective in relation to the remanufacturing industry.

\section{Exploring Lean Manufacturing}

The increasing popularity of lean has been driven by studies highlighting the dramatic results of lean implementation. An early study regarding the power of lean was undertaken by Womack, Jones, Roos and Carpenter (1990), which revealed that the efficiency of Japanese automotive manufacturers far exceeded that of their American and European counterparts, where Japanese factories required half the effort of American factories. This figure was even more dramatic when compared to Europe: Japanese manufacturers required only a quarter of the effort of the average European plant. One of the reasons given to explain this productivity gap was employee empowerment. Employee participation in problem solvings in the Japanese firm was $72 \%$ in comparison to their US counterpart, where it was only $9 \%$. In addition, in the Japanese factories, employees put forth on average 32.5 ideas each, with an implementation rate of $87 \%$. This far exceeds the rates in the US, where employees suggested just 0.11 idea each, with an implementation rate of 32\% (Robinson, 2009). As such, it is not surprising that lean production has become of topic of interest to many scholars.

The origin of lean production is the long-term orientation of companies striving for excellence, where lean production can be summarised as "doing more with less". Although this definition over-simplifies the concept of lean production, the phrase accurately conveys the basic principle of lean production: utilising resources in an effective way.

Just-In-Time (JIT), Toyota Production System (TPS) and lean production are interrelated concepts, but the terms cannot be used interchangeably, as each is distinct and has a different emphasis. The key distinguishing feature of lean production is that it seeks to minimise waste. The number of studies of JIT has declined in recent years, while there has been a consistent increase in interest in lead production (Papadopoulou \& Özbayrak, 2005). This indicates that lean manufacturing is a more popular concept than JIT.

Ostlin and Ekholm (2007) conducted a study examining the application of lean principles in remanufacturing using a toner cartridge remanufacturer as a case study. The main problems that were identified in the case company were the high variability of processing time, and uncertainty related to the raw materials. By overcoming these issues, the remanufacturer could significantly improve the performance of the remanufacturing system.

The advocates of lean productions argue that the concept is universal, so it can be implemented regardless of industry type (Womack et al., 1990). They argue that lean production combines "craft production" and "mass production" to create a powerful concept that is applicable in any manufacturing company. Further, they claim that a lean production system would be the most preferred production system for any company.

From the production perspective, JIT is the backbone of lean principles. This is due to the fact that use of JIT is the main factor contributing to higher value-added in comparison to batch and mass production systems. For this reason, lean is believed to be the most dominant production system (Womack et al., 1990). Further, Womack et al. (1990) have suggested that batch production is an illusion only, because it relies too much on common sense, preventing the streamlining of production flow which would create added-value for customers'. On the other hand, streamlining production flow is the only way to compete in the global market. Ideally, production flow should be free from interruption so that it can operate efficiently. However, in practice, this is difficult to achieve.

\section{Doubts Regarding the Universality of Lean Production}

It seems there is not any empirical evidence that production flow can run smoothly in remanufacturing companies. When production flow for creating value to customers cannot be evidenced in remanufacturing companies, the universality of lean can be questioned. The remanufacturing industry is unique; it is extremely difficult, if not impossible, to adopt a production flow system. Guide Jr, Jayaraman, Srivastava and Benton (2000) highlighted eight difficulties that make remanufacturing production systems more complex than conventional production systems: (a) uncertainty regarding the time and quantity of incoming cores; (b) difficulty balancing returns and demands; (c) the need to undertake disassembly; (d) uncertainty of material recovery rates; (e) the need to organise reverse logistics; 
(f) uncertainty when matching components during reassembly; (g) stochastic routings to process components; and (h) significant differences in the time needed to process materials.

Lean production is not a new concept, developed to substitute an existing one; rather, it complements the existing concepts and should not be regarded as a replacement of the former (Cooney, 2002). Lean has been criticised due to its emphasis on the role of human resources in the production process (Engström, Jonsson \& Medbo, 1996). However, in practice, the percentage of human resource cost of the production cost is roughly $5-10 \%$ for some industries. Meanwhile, the remanufacturing industry is a labour intensive industry, meaning there is much room for increased efficiency; for instance, improvement of employee skills will lead to an improved production process, although external factors might hinder the improvement of employee skills. Remanufacturing companies operate in an after-market industry in which product innovation occurs rapidly, meaning improving employee skills is more difficult.

The working environment in remanufacturing is highly uncertain, primarily with regard to three factors: when the used products will be returned by customers (time uncertainty); how many used products will be returned (quantity uncertainty); and in what condition products will be returned (quality uncertainty). These uncertainties lead to variations in the remanufacturing process, which is more difficult to manage in comparison to conventional manufacturing process. Guide Jr et al. (2000) went further, identifying seven uncertainties: uncertainty in timing and quantity of returns; in balancing returns with demands; in the disassembly process; materials recovery uncertainty; uncertainty in reverse logistics; in material matching restrictions; in stochastic routings for materials; and, highly variable processing times.

Although a large number of studies have demonstrated the benefits of lean production (Gurumurthy \& Kodali, 2009), there are some counter arguments concerning the benefit of its implementation. For instance, lean is not suited to all organisations, and its adoption must be adjusted to specific situations and business needs (Cusumano, 1994). In addition, lean adoption may only be appropriate in certain situations, for example during economic difficulties, as was experienced by Nissan, Honda, and Mazda, which were all acquired by other companies. Arguably, the success of lean production in Japan was due to the unique macro conditions of that time, arising out of the very specific characteristics of the Japanese economy, a stable and high volume demand from the domestic market (Lewis, 2000).

Another factor that might hinder lean production implementation is organisational stickiness. Companies experienced difficulties to transfer lean from headquarters to branches abroad (Danese et al., 2017). The contingency and complexity of the context determine the success of lean transfer (Danese et al., 2017; Lewis, 2000) and there is no one best practice that can be immediately implemented (Bamford et al., 2015). Furthermore, Lewis (2000) has put forth a number of critiques regarding the generalisability of lean, supported by empirical evidence. Therefore, companies attempting to implement lean should consider the context, history, and culture of the organisation. However, some authors further argue that lean is not universally applicable, as the assumptions that it relies upon are not always relevant (Cooney, 2002). Others have similarly criticised lean, citing the fact that it was originally developed in Japan, and thus might be not suitable to be implemented in a different culture. Furthermore, technology changes may also or further reduce its relevance (Cusumano, 1994).

To overcome its limitations, partial and iterative lean implementation is more feasible than full implementation (Bamford et al., 2015). This is due both to the fact that lean will require some adjustment in light of contextual differences, as discussed above, as well as the need for an incremental approach (Lee \& Jo, 2007). However, in order to achieve maximum results, full adoption is preferred. Therefore, analysis of lean adoption should be undertaken in stages so that improvements resulting from relevant lean techniques can be clearly identified (Bamford et al., 2015).

The impact of lean on profitability is not well understood, though it has been observed that it only affects profit volatility for companies adopting lean at a high level (Oliver \& Hunter, 1998). The lack of understanding regarding the true impact lean implementation on profitability is even more pronounced in the remanufacturing environment due to contextual differences. The Toyota Production System, where lean production emerged, and the wider 
remanufacturing industry, differ significantly. Thus, there is a need to better understand the applicability of lean principles in the remanufacturing industry. Thus, this study will address the following research questions:

\section{RQ1. What are the challenges of lean manufacturing adoption in remanufacturing companies?}

RQ2. How do remanufacturing companies assimilate lean manufacturing in their production systems?

\section{Research Method}

\subsection{Case Study Method}

This is a qualitative study using the case study method (Yin, 2009; Eisenhardt, 1989). The use of this method makes the present study different from many previous studies investigating this topic. Most previous studies have adopted positivist paradigms, conducting operations research based on assumptions that are difficult to test in real life situations (Flynn, Kakibara, Schroeder, Bates \& Flynn, 1990). Therefore, conducting research adopting a different methodology and philosophical stances provides a significant contribution to existing knowledge.

The data was collected in various ways over a total period of 7 months. Interviews were conducted, which lasted for between 0.5 to 2 hours depending on the progress of the discussion. In total, 24 managers, supervisors and employees participated in this study. In addition to data collected from observations, interviews and group discussions, a number of secondary data sources were also consulted, such as monthly production reports, accounts, and so on.

There are strategies that can be utilised in case study research to ensure that the quality is maintained, including validity evaluation (Flynn et al., 1990; Yin, 2009) and the use of triangulations (Easterby-Smith, Thorpe \& Lowe, 2002; Yin, 2009). Triangulation was employed during data collection to ascertain that all source of evidence provide consistent data. Validity refers to "the correctness or credibility of a description, conclusion, explanation, interpretation, or other sort of account" (Maxwell 2009: page 87). This was achieved through a series of assessments (Flynn et al., 1990; Yin, 2009). Internal validity was assured using pattern matching and addressing rival explanation while external validity was ensured by using replication logic in multiple case studies. Using multiple source of of evidence and asking ke informatns to review the case study reports are among techniques used to ensure validity of constructs.

\subsection{Case Companies}

The use of case study requires the researcher to ensure that the sample composition allows for direct and indirect replication (Yin, 2009). The purpose of using multiple cases is thus not to increase the sample size (as might be the case when conducting a survey), but rather to increase the understanding of a population through replication (Meredith, 1998; Eisenhardt, 1989). Company A and B are automotive remanufacturing companies, while $\mathrm{C}$ is a jet engine remanufacturer. Company $\mathrm{C}$ was included to examine the applicability of lean production in another context, as past studies have largely focused on the automotive sector. A brief overview of the case companies is presented in Table 1.

\begin{tabular}{|l|l|l|l|}
\hline \multicolumn{1}{|c|}{ Company A } & \multicolumn{1}{c|}{ Company B } & \multicolumn{1}{c|}{ Company C } \\
\hline Type of remanufacturer & Independent & Contract & $\begin{array}{l}\text { Original Equipment } \\
\text { Manufacturer (OEM) }\end{array}$ \\
\hline Cores circulation & Open-loop supply chain & Open-loop supply chain & Closed-loop supply chain \\
\hline Type of customers & Retail & Industrial & Industrial \\
\hline Company size & SME & SME & Large \\
\hline Number of employees & 37 & 75 & 620 \\
\hline Products remanufactured & Torque converters & Gearboxes & Jet engines \\
\hline Volume of production per year & 740 & 3000 & 400 \\
\hline
\end{tabular}

Table 1. Case companies 


\subsubsection{Company $\mathrm{A}$}

Company A is an independent company that remanufactures gearboxes; it has been operating since 1976, and has remained a family business. The company employs 37 staff to remanufacture Torque converters, which are received directly from customers. The company predominantly adopts make-to-order system. The orders are typically small and come from individual customers with specific needs. Adding to the complexity, there is uncertainty regarding the time of orders arrival. Consequently, there is high fluctuation in orders, which causes an excess of idle capacity.

In Company A, there is no specific procedure, practical guidance, or customised tools for the remanufacturing process, which is carried out in a straightforward way using standard tools that can be obtained from general market, and there is only a limited number of detailed and specific instructions for each process. The company employs staff with multiple skills rather than specific ones. The managing director explained that it is difficult to equip employees with a range of skills, since it is a slow learning process that takes a long time.

\subsubsection{Company B}

Company B is a contract remanufacturer based in Bristol that has been operating since 1978. The customers are automotive manufacturing companies including FCSD, General Motors, Volvo, Mitsubishi Motors, Jaguar, and Land Rover. The company employs 75 staff with different skill sets and expertise levels in order to produce approximately 15,000 remanufactured products, generating roughly $f^{\prime} 7$ million per year.

The company is predominantly in the business of gearbox remanufacturing, which accounts for $75 \%$ of its operations. The cores from OEMs are stored in a 30,000 square metre warehouse facility, which can hold up to 20,000 cores at any one time. The company operates made-to-order production systems to fulfil orders placed by the customers - i.e. the OEMs. Despite this, the remanufacturing facility in the company is not supported by flexible tools and equipment.

The company has a research and development $(\mathrm{R} \& \mathrm{D})$ team that designs customised tools and equipment, set-up production facility and finds the best way to remanufacture the products. The investment needed to set-up a facility to remanufacture a gearbox model can be as much as $f, 3,000$, but this figure is spread over an approximately fiveyear production period. In addition to this, the operators of tools and equipment must attend in-house training to acquire specific skills and knowledge. The company organises formal training and evaluation for its employees, and an $\mathrm{R} \& \mathrm{D}$ team designs the materials for this.

\subsubsection{Company $\mathrm{C}$}

Company $\mathrm{C}$ is one branch of a leading jet engine manufacturer, and focuses on remanufacturing. All remanufacturing activities conducted in this company are done so under leasing agreements with airline companies based on a power-by-the-hour system. The customers are highly diversified, consisting of 120 customers ranging from commercial, government, and military sectors, with production volumes of approximately 400 engines per year.

The company operates a made-to-order production system to fulfil customer orders. Due to the high value of the product and high number of components required, the company requires robust production planning and control systems supported by reliable forecasting. Unreliable production planning and control leads to a large inventory and inefficient remanufacturing process.

\subsection{Benchmarking for Lean Implementation}

Benchmarking has been viewed as a powerful tool for self-assessment and comparison. Self-assessment is a critical process in the use of benchmarking during lean production implementation, as it provides baseline indicators for current performance status (Gurumurthy \& Kodali, 2009). It also allows companies to carry out a close comparison with best practice companies (Lewis, 2000), where the identification of relative weaknesses and strengths could be used to improve efficiency and productivity (Gurumurthy \& Kodali, 2009).

Despite many claims that benchmarking is only useful in providing operational-level indicators, benchmarking has produced strategic-level information useful for strategic decision-making. Saunders, Mann, and Smith (2007) utilised 
benchmarking to identify strategy deployment practices accross different organisations. Although there were differences in terms of industry type, organisational size, culture, and market, some commonalities were found.

However, even within the same industry, lean production still requires modification. The Hyundai Production System (HPS) was not developed from scratch; rather, it is a modification of the Toyota Production System made to adapt to the company's unique characteristics. The adaptation of TPS into HPS involved a complex process and organisational learning (Lee \& Jo, 2007). If adaptation in the same industry requires such great effort, then it can be reasonably expected that adaptation in another industry - i.e. remanufacturing industry - will even require even more effort.

There has been a plethora of studies using benchmarking in the manufacturing sector, and a comprehensive literature review on this was carried out by Gurumurthy and Kodali (2009). One of the early studies that benchmarked lean implementation was carried out by Comm and Mathaisel (2000). They pointed out that benchmarking is an appropriate method for studies of lean implementation, as lean requires relative measures that depend on various internal and external factors. Further, they argued that lean can be applied in non-familiar industries, such as military aerospace products.

Any implementation of lean production should acknowledge the individual differences between companies, and furthermore must consider the existing condition of the companies - e.g. the technology, people, dominant resource, strategic direction, business performance, buyer supplier relationship, and so on. These existing conditions require different routes to lean implementation (Lewis, 2000), and, consequently, result in different sources of competitive advantage.

\section{Empirical Findings}

\subsection{The Challenges of Lean Adoption in Case Companies}

This section will compare the characteristics of remanufacturing companies and conventional manufacturing companies. Table 2 presents a number of characteristics of the case companies and compares them with the lean manufacturing model proposed in literature (Liker \& Meier, 2006).

\subsubsection{Long-term Orientation}

The basic requirement for lean implementation is a long-term orientation. To some extent, companies should sacrifice short-term for long-term benefit (Rymaszewska, 2014). Unfortunately, long-term orientation is not an easy position for remanufacturers to take, since they operate in an after-market industry, where it is not easy to identify the types of products that will be manufactured by OEMs and returned by customers. Sometimes, products introduced by OEMs are not successful, and therefore remanufacturers never receive the cores from those failed products. Thus, it is important for remanufacturers to forecast which new products introduced by OEMs will be successful.

Managers should view the process of lean adoption as a journey rather than a race to reach the finish line. Unfortunately, the interviews revealed that managers attempt to gain benefit from lean implementation as soon as possible. One possible explanation for this is that remanufacturing companies typically have limited resources, so certain large investments will have a high opportunity cost. In the case that a company intends to invest for the long-term - as was found in Company B in this study - this money will only be spent on something more general which is always be useful regardless the situation. This is due to the fact that product innovation has made it difficult for OEMs to have a long-term orientation. Compared to Company A and B, which remanufacture torque converters and gearboxes, respectively, Company $\mathrm{C}$ remanufactures jet engines, which have a much longer life cycle. Thus, it is much more worthwhile for Company $\mathrm{C}$ to implement a long-term strategy of lean production. 


\begin{tabular}{|c|c|c|}
\hline & Remanufacturing case companies & Toyota Production System \\
\hline Time perspective & $\begin{array}{l}\text { Short-term orientation. Remanufacturers cannot } \\
\text { determine what types of products will be } \\
\text { remanufactured, although there are various options. }\end{array}$ & $\begin{array}{l}\text { Long-term orientation. Managers should } \\
\text { assign higher priority to long-term } \\
\text { decisions, although the company may have } \\
\text { to sacrifice short-term benefits. }\end{array}$ \\
\hline Process choice & $\begin{array}{l}\text { Batch production system with much interruption } \\
\text { between the processes. }\end{array}$ & $\begin{array}{l}\text { A continuous production system is } \\
\text { developed so that problems can be } \\
\text { identified. }\end{array}$ \\
\hline Production trigger & $\begin{array}{l}\text { Some adopt a pull production system, though there is a } \\
\text { lot of inventory to minimise idle capacity through } \\
\text { production leveling. }\end{array}$ & $\begin{array}{l}\text { Utilises a pull rather than a push } \\
\text { production system, so that overproduction } \\
\text { and unnecessary inventory can be avoided. }\end{array}$ \\
\hline Workload leveling & $\begin{array}{l}\text { Fluctuating demand and cores availability have created } \\
\text { difficulty for remanufacturing companies to level out } \\
\text { workload. Workload leveling can be undertaken at the } \\
\text { expense of increasing unnecessary inventory. }\end{array}$ & $\begin{array}{l}\text { Adopts beijunkan to level out the workload } \\
\text { and minimise idle capacity. }\end{array}$ \\
\hline $\begin{array}{l}\text { Quality } \\
\text { management }\end{array}$ & $\begin{array}{l}\text { Knowledge development is not linear. There is a lot of } \\
\text { trial and error to find new ways of completing } \\
\text { remanufacturing tasks. }\end{array}$ & $\begin{array}{l}\text { Develops a high quality culture of doing } \\
\text { things right first time. }\end{array}$ \\
\hline $\begin{array}{l}\text { Task } \\
\text { standardisation } \\
\text { and employee } \\
\text { empowerment }\end{array}$ & $\begin{array}{l}\text { There is a high level of employee empowerment, but task } \\
\text { standardisation is very difficult. }\end{array}$ & $\begin{array}{l}\text { Task standardisations is the basis for } \\
\text { continuous improvement and employee } \\
\text { empowerment. }\end{array}$ \\
\hline Visual control & $\begin{array}{l}\text { The use of visual control is limited, and primarily to } \\
\text { standardise quality during product inspection. }\end{array}$ & $\begin{array}{l}\text { A visual control system is used to identify } \\
\text { hidden problems. }\end{array}$ \\
\hline $\begin{array}{l}\text { Technology } \\
\text { support }\end{array}$ & $\begin{array}{l}\text { The use of technology is limited. Most processes are } \\
\text { undertaken manually with general tools and some } \\
\text { customised equipment developed in-house. }\end{array}$ & $\begin{array}{l}\text { The use of technology is recommended to } \\
\text { support an efficient production system. }\end{array}$ \\
\hline Leadership & $\begin{array}{l}\text { Leaders should possess a good understanding of external } \\
\text { trends and market conditions. They should be good at } \\
\text { forecasting future market trends, particularly regarding } \\
\text { product life cycles. }\end{array}$ & $\begin{array}{l}\text { Develops leaders internally who uphold the } \\
\text { company philosophy, and individuals } \\
\text { within the company share its vision. }\end{array}$ \\
\hline $\begin{array}{l}\text { Employee skills } \\
\text { and knowledge }\end{array}$ & $\begin{array}{l}\text { Employees tend to find better opportunities and future } \\
\text { prospects in other companies because the } \\
\text { remanufacturing industry is small. Employee skills } \\
\text { development is not structured, as it responds to after- } \\
\text { market needs. }\end{array}$ & $\begin{array}{l}\text { Helps staff to develop exceptional skills, } \\
\text { cultivates a distinct and widespread culture } \\
\text { accross all individuals within the company. }\end{array}$ \\
\hline $\begin{array}{l}\text { Upplier } \\
\text { relationship }\end{array}$ & $\begin{array}{l}\text { Difficult to identify cores suppliers that are eager to } \\
\text { supply materials in the long-term. To some extent, } \\
\text { remanufacturers might compete with the suppliers to } \\
\text { obtain cores directly from customers due to scarcity of } \\
\text { raw materials. }\end{array}$ & $\begin{array}{l}\text { Treats companies involved in the supply } \\
\text { chain as partners and supports them in } \\
\text { improving their operations. }\end{array}$ \\
\hline Problem-solving & $\begin{array}{l}\text { Technical skills are very important. Even managers } \\
\text { should have detailed technical skills to be able to } \\
\text { undertake remanufacturing processes. }\end{array}$ & $\begin{array}{l}\text { Direct observation of certain problems. } \\
\text { Staff must posseses first-hand knowledge } \\
\text { before deciding ("Genchi Genbutsu"). }\end{array}$ \\
\hline $\begin{array}{l}\text { Decision-making } \\
\text { process }\end{array}$ & $\begin{array}{l}\text { Many decisions are made case-by-case. Some cross- } \\
\text { functional collaboration is also needed before deciding. } \\
\text { Regarding the make or buy decision, in many cases it is } \\
\text { not clear which is more beneficial. }\end{array}$ & $\begin{array}{l}\text { Decisions are reached via consensus after } \\
\text { reviewing alternatives, but the } \\
\text { implementation is quick. }\end{array}$ \\
\hline $\begin{array}{l}\text { Learning } \\
\text { organisation }\end{array}$ & $\begin{array}{l}\text { Attempt to accummmulate knowledge from past } \\
\text { experience. There is a learning process in } \\
\text { remanufacturing companies, its purpose is not to achieve } \\
\text { efficiency but to maximise the value of recovered cores. }\end{array}$ & $\begin{array}{l}\text { Learning from experience to develop best } \\
\text { practice ("hansei") and undertake } \\
\text { continuous improvements ("Kaizen"). }\end{array}$ \\
\hline
\end{tabular}

Table 2. Benchmarking of case companies with TPS 


\subsubsection{Process Choice}

Lean production suggests developing a continuous production system so that problems can be identified (Liker \& Meier, 2006). However, in general practice, process choice in remanufacturing companies can be grouped into two categories. The first group consists of companies organising job shops, with repetitive tasks and complex routings. This typically occurs within big companies that remanufacture complex cores. Evidence for this was found in Company A and B. In Company A, orders are received in small numbers from individual customers with specific needs. Adding to the complexity, there is uncertainty regarding when orders will arrive. Similar to Company A, Company B utilises a made-to-order system to fulfil orders from its customers - i.e. the OEMs. Although the company holds a considerably high number of cores, it attempts to minimise its stock of finished products by dispatching finished products to customers as soon as the remanufacturing process has completed.

The second group consists of smaller sized remanufacturers, who remanufacture simpler products such as alternators, turbo chargers, starters, and so forth. These plants typically use batch production, which features many repetitive tasks and similar routings (Ferrer \& Whybark, 2001). In Company C, the orders come from airline companies that have power-by-the hour leasing agreements with the company, based on an agreed cost for an engine to fly for one hour.

\subsubsection{Production Trigger}

Lean production suggests the use of a pull rather than a push production system, so that over-production and unnecessary inventory can be avoided. In general, the case companies adopt a pull production system, although there is a lot of inventory in order to minimise idle capacity. Company A predominantly adopts a made-to-order remanufacturing process, which starts as soon as the orders from customers have been received. This is typical in independent remanufacturers, which tend to be small and medium enterprises (SMEs). Small independent remanufacturers typically adopt made-to-order and compete in uncertain as well as complex environments (Ferrer \& Whybark, 2001), and the process only starts once the customer order is received (Tang, Grubbstrom \& Zanoni, 2007). Company B uses a production line for its remanufacturing operations, and holds approximately 20,000 core stocks at any one time as raw materials for the remanufacturing production line. Although the company remanufactures different product models, this can be offset by the high volume of the cores, in order to reduce the fixed cost.

Meanwhile, Company $\mathrm{C}$ does not have sufficient cores supply to streamline material flows during the remanufacturing process. Rather, the company utilises a batch system supported by early information collected from Engine Health Management System (EHMS) so that idle capacity and uncertainty can be reduced. This finding also confirms those of previous studies regarding the fact that information can reduce uncertainties and result in a reduction in total holding and shortage costs (Ketzenberg, Souza \& Guide, 2003; Ketzenberg, Laan \& Teunter, 2009).

\subsubsection{Workload Levelling}

Workload levelling is one of key foundations of lean manufacturing (Womack et al., 1990). Fluctuating demand and cores availability make it difficult for remanufacturing companies to level out workload. Workload levelling can be undertaken, but at the expense of increasing unnecessary inventory. In Company B, the high volume of cores can be used for production levelling in almost any remanufacturing process. Accordingly, continuity of cores supplies can help shop floor employees to reduce idle capacity and increase utilisation rates (Vinodh, Nachiappan \& Kumar, 2012). A lack of attention to the quality of cores can result in either not enough, or too many cores. An increase as little as $1 \%$ in uncertainty regarding the quality of cores can lead to a $5 \%$ increase in costs (Teunter \& Flapper, 2011). Of the three cases, only Company B utilises production levelling to distribute production evenly across different time periods. Reducing idle capacity is important since the company incurs a large fixed cost investment to set up the facility. 


\subsubsection{Quality Management}

Lean manufacturing also suggests developing a culture of high quality, of getting things right first time (Liker \& Meier, 2006). However, in most of the case companies, the development of quality management systems is not linear, and there is a lot of trial and error to find new ways of completing remanufacturing tasks. For instance, employees working in Company $A$ accumulate knowledge informally through learning by doing. The company does not have a formal quality management process. Rather, there is a long process of trial and error to find new ways of undertaking the manufacturing process. A more structured method was found in Company $A$, where an R\&D team designs the materials for employee training and evaluation. The company devotes a set amount of financial resources to support the $\mathrm{R} \& \mathrm{D}$ team in improving the manufacturing process.

The process of quality control in lean manufacturing is also different to that in remanufacturing. Lean manufacturing suggests the use of samples at each step of the production process, while the first step of quality management in the remanufacturing process is checking the quality of cores. Quality checking in remanufacturing does not use samples; rather, all cores are checked individually. This process of quality control takes up a large proportion of the remanufacturing process, but makes subsequent processes easier. Quality control provides direction regarding what should be done next with each core; also, the quality management from the first process can provide information needed to reduce variation in the remanufacturing process.

Another quality management technique used by one of the case companies - i.e. Company B - to cope with variations is cores sorting. Cores sorting can be used as a form of gate keeping to increase homogeneity in the quality of cores that arrive at the factory, to facilitate easier streamlining of production (Zikopoulos \& Tagaras, 2008).

\subsubsection{Task Standardisation and Employee Empowerment}

In the case companies, there is a high level of employee empowerment, but task standardisation is very difficult. In Company A, the employees even remanufacture different models of torque converter in the same location, where various tasks performed include disassembly, cleaning, inspection, and testing. Employees in Company A are multiskilled and easily transferred between different positions, and given flexibility to carry out different tasks. This finding supports the conclusions of (Guide, Souza \& van der Laan, 2005), who observed that workers in remanufacturing companies tend to use general tools as opposed to specific ones. These staff should also be given more responsibility and job enrichment (Westkamper, Feldmann, Reinhart \& Seliger, 1999), for example by combining assembly and disassembly tasks.

Meanwhile, in Company B, employees' tasks are more standardised. This is partly due to the larger size of the company in comparison to Company A. The employees in Company B are required to attend training to gain skills so that they can perform remanufacturing tasks efficiently. The workers are equipped with specific skills to remanufacture certain product models; employees are transferrable to different phases of remanufacturing, but not to different product models. Their skills are developed in-house, since there is no training provider or formal education that provides the relevant training. This evidence indicates that there is greater task standardisation in Company B than in Company A.

\subsubsection{Technology Support}

Lean manufacturing recommends the use of technology to support an efficient production system (Liker \& Meier, 2006). Several technologies have been developed to support the remanufacturing process, such as embedded devices (Ilgin \& Gupta, 2011), active disassembly (Chiodo \& Ijomah, 2012; Ijomah \& Chiodo, 2010), and sensor technology (Boks \& Tempelman, 1998).

The use of embedded devices can significantly reduce the costs associated with holding, back orders, disassembly, disposal, testing and transportation, and therefore increase revenue and profit (Ilgin \& Gupta, 2011). Embedded technology thus offers benefits throughout the product life cycle (Boks \& Tempelman, 1998). However, one of these technologies, active disassembly (Chiodo \& Ijomah, 2012; Ijomah \& Chiodo, 2010), is currently too expensive to be adopted for mass production (Sundin et al., 2012). 
Most of the technologies used in the remanufacturing process are designed to minimise workload and consequently reduce cost. Nevertheless, the use of technology in the remanufacturing case companies is limited. All the technologies mentioned above are still in their infancy, and are not yet ready for industrial application. Where they are available, the acquisition cost of such technologies is extremely high. The managers of the case companies explained that rather than adopting such technologies, it is more economically beneficial for employees to use manual techniques and existing tools.

\subsubsection{Leadership and Collaboration}

Lean manufacturing recommends the internal development of leaders who uphold the company philosophy, and individuals within the company should share its vision. Leaders in remanufacturing companies should meet certain additional criteria; they should possess a good understanding of external trends and market conditions; and, they should be good at forecasting future market trends, particularly regarding product life cycles. All company employees should share a common understanding that the company should maximise the reclaimed value from cores.

There is strong evidence regarding collaboration for decision making between employees in remanufacturing case companies. In addition, cross-functional collaboration is common to address problems that cannot be solved within a function. Two of the case companies are SMEs - Company $A$ and $B$ - where there is a casual workplace environment that constitutes a supportive environment for collaboration. In these companies, employees are given responsibility to make decisions without needing to consult with supervisors. In many cases, they are in a better position to make such decisions, due to the skills that they have accumulated over a long period of time.

\subsubsection{Employee Skills and Knowledge}

Lean manufacturing emphasises the importance of long-term development of employee skills and cultivating a distinctive culture. These culture should be spread across all individuals at different levels within the company (Liker \& Meier, 2006). In addition, the management of skills and knowledge in remanufacturing companies is different from that in manufacturing companies. The technical skills of lower-level employees are developed internally and accumulated over a long time. However, the managers in remanufacturing companies tend to find better opportunities and future prospects in other companies, due to the small size of the remanufacturing industry (Lind et al., 2014). Another reason why managers seek better opportunities in other industries is that the development of managerial skill in remanufacturing companies is poor and unstructured, as it follows the needs of the after-market business.

OEMs possess much better product knowledge than remanufacturers, and any support from OEMs would be useful for remanufacturers. Remanufacturing complex technical products requires high level skills and knowledge of product specification details. Unfortunately, there is limited empirical evidence regarding OEMs who interested in supporting remanufacturing companies. Company B receives knowledge transfer from some OEMs only, and large companies such as Land Rover and BMW as reluctant to share knowledge with Company B.

\subsubsection{Supplier Relationship}

Empirical evidence suggests that a strong relationship with OEMs, as cores suppliers, improves the adoption of lean manufacturing. The inter-organisational relationship between OEMs and remanufacturers can support efficient remanufacturing operations (Ijomah, 2009) as OEMs have greater accessibility to cores (Östlin et al., 2008). The relationship with OEMs as cores suppliers is important, as it influences the number of cores received and thus can help maintain a stable production flow (Lind et al., 2014). Company C, an OEM remanufacturer, has a better ability to predict cores arrival, minimise idle capacity, and manage cores volume fluctuation. Although the company remanufactures highly complex products and utilises a batch production process, it has a more efficient production system.

At the other extreme, Company $\mathrm{A}$, which is an independent remanufacturer, is vulnerable to production interruptions. In addition to receiving a limited number of cores to remanufacture, Company A assigns a higher priority to saving the parts and recovering their value than on streamlining material flows. This is due to the fact 
that capturing residual value is the source of profitability, making the efficiency that results from streamlining production flow less important.

A supply chain approach to developing a relationship with cores suppliers should be used. Developing a closed relationship with suppliers is not only useful in a manufacturing context, but also in a remanufacturing context. A good cores supplier relationship can reduce risk, uncertainty, and costs, and increase the value offered to customers. Unfortunately, developing mutual trust in the supply chain is not an easy task in the after-market industry. Very often, remanufacturers might be competing with cores suppliers due to the scarcity of raw materials (Vinodh et al., 2012). This is often cited as the reason for failure to develop integrated and well-coordinated buyer-supplier relationships (Cox \& Chicksand, 2005).

\subsubsection{Problem-solving}

Lean manufacturing requires direct observation to solve certain problems, where one must possess first-hand knowledge before deciding ("Genchi Genbutsu"). This can also be seen in remanufacturing contexts, where employees are required to have detailed and specific technical skills. While in a lean manufacturing environment managers are typically not required to have such skills, and instead empower front-line employees to solve problems, managers in remanufacturing companies are required to possess the relevant skills themselves. A possible explanation for this is that the purpose of remanufacturing companies is not to create value from making new products, but to capture the residual value of the cores. In many cases, the most important consideration during problem-solving is how to maximise the value that is recovered from cores.

In remanufacturing companies, problem-solving mostly relies upon knowledge accumulated from past experience. The skills and knowledge accumulated from the remanufacturing process itself are scare and unique, making it is difficult to copy and therefore build a platform for competitive advantage. The transferable skills and knowledge created through unique remanufacturing processes have high economic value. Due to the limited career opportunities in remanufacturing companies, many talented staff are acquired by larger companies in different industries offering greater prospects (Lind et al., 2014). OEMs are interested in the skills and knowledge developed by remanufacturing staff; this is because, to some extent, OEMs and remanufacturers compete with one another. OEMs can use the skills and knowledge of remanufacturing employees to avoid market cannibalisation of new products by remanufactured products (Atasu, Guide \& Van Wassenhove, 2010; Guide Jr \& Li, 2010)

\subsubsection{Learning Organisation}

In lean manufacturing, the learning process involves experience leading to the development of best practice (bansel), and undertaking continuous improvement (Kaizen). This is because lean is not only concerned with tools and techniques; it is about a way of thinking. Lean can only be achieved when its philosophy is embedded in the company culture. Learning in lean production requires a long-term orientation to enable progression and the accumulation of knowledge (Liker \& Meier, 2006).

By contrast, in remanufacturing companies, learning from past experience is mostly driven by external factors, as the companies operate in the after-market industry. All of the case companies are designed to be flexible organisations. The main purpose of learning within these companies is to develop an increasingly efficient production system that can capture as much residual value as possible from returned products. The existing literature states that learning offers two benefits: first, it increases the efficiency of processes developed within the company; and second, it increases resilience when facing new situations (Sitkin, 1992). In a remanufacturing environment where the product life cycle is shorter, the second benefit is more important than the first, as remanufacturers must adapt to changing environments more frequently, and in a rapid manner.

Learning leads to all individuals within remanufacturing companies possessing a common understanding. All personnel within the case companies acknowledged the need for them to be aware of current market trends, and the new technologies adopted by OEMs. These have created a culture of learning amongst individual employees in the case companies. All of the managers in the case companies agreed that they need to stay up to date with the latest trends introduced by OEMs. Consequently, they should continually seek new and better ways of doing things to facilitate continuous improvement. 


\subsection{How Remanufacturing Companies Assimilate Lean Manufacturing}

In addition to the challenges of lean adoption in remanufacturing companies that have already been discussed, there are a number of supportive and prohibitive factors affecting the assimilation of lean principles, which are presented in Table 3.

\begin{tabular}{|c|c|}
\hline Supportive factors & Prohibitive factors \\
\hline $\begin{array}{l}\text { - The nature of remanufacturers as flexible organisations } \\
\text { able to adapt to external conditions. }\end{array}$ & $\begin{array}{l}\text { - Shortening product life cycles makes investment in } \\
\text { process innovation less feasible. }\end{array}$ \\
\hline $\begin{array}{l}\text { Decentralised decision-making enables decision-makers } \\
\text { to gain insights directly from the source. }\end{array}$ & $\begin{array}{l}\text { - Unstructured employee skills development due to } \\
\text { uncertainty regarding the types of products being } \\
\text { remanufactured. }\end{array}$ \\
\hline $\begin{array}{l}\text { - Homogenous understanding of company culture. All } \\
\text { people in the company have a common understanding } \\
\text { regarding the need to maximize the reclaimed value from } \\
\text { cores. }\end{array}$ & $\begin{array}{l}\text { - Uncertainty in timing and quantity of cores returns make } \\
\text { JIT implementation in remanufacturing companies very } \\
\text { difficult. }\end{array}$ \\
\hline $\begin{array}{l}\text { Remanufacturing process requires decisions to be made } \\
\text { case-by-case. Most problem-solving requires first-hand } \\
\text { knowledge ("Genchi Genbutsu"). }\end{array}$ & - Limited number of cores, as the raw materials. \\
\hline $\begin{array}{l}\text { - Remanufacturing companies develop a dynamic culture } \\
\text { to cope with uncertain external conditions, such as } \\
\text { unstable cores supply, shortening product life cycles, and } \\
\text { types of product returns. }\end{array}$ & $\begin{array}{l}\text { Difficulty standardising tasks and adopting automation } \\
\text { due to uncertainty in the remanufacturing process. }\end{array}$ \\
\hline
\end{tabular}

Table 3. Supportive and prohibitive factors affecting lean assimilation in the remanufacturing industry

The remanufacturing companies follows a different path from their manufacturing counterparts to assimilating lean. In addition, the case companies have different level of lean implementation, as indicated by the number of tools they utilise. Bamford et al. (2015) demonstrated that different starting points for lean implementation will lead to different results. Similar evidence has been observed in the remanufacturing industry, where each remanufacturer utilises different business processes, making them unique. Although there are some generic remanufacturing processes available, how these activities are undertaken leads to differences in competitive advantage.

In this study, the characteristics of lean manufacturing implementation in the case companies varied widely, leading to different routes to lean adoption shaped by internal factors within the companies, as well as the contextual factors related to where the company operates. Lean implementation in Company $B$ was initiated with a large investment in $\mathrm{R} \& \mathrm{D}$ to develop customised tools and equipment. A large investment in remanufacturing process line equipment is economically feasible. Company B conducted some benchmarking against conventional manufacturing companies in order to adopt lean manufacturing. This was possible due to the high volume of available cores as well as the high demand for remanufactured products. The result was that the company was able to produce an assembly line for the remanufacturing process.

The success of lean implementation in Company $B$ has had clear consequences. It has resulted in a reduced number of staff, who are encouraged to work "smarter and harder". Lean implementation has successfully improved productivity, but it has also placed some pressure on existing employees, which, to some extent, has a negative effect on employee morale. This was also one of the drawbacks highlighted in a previous study (Cusumano, 1994).

On the other hand, Company $A$, an independent remanufacturer with a low volume and high variety of cores, relies on the skills of its employees to improve efficiency. Knowledge accumulation from organisational learning is the backbone of this strategy, which is unsurprising, as most low-level employees have worked for the company for more than 20 years. The clearest result from this accumulated knowledge is the lower number of rejected cores, and higher rate of product recovery. 
One of the case companies demonstrated unconscious lean adoption. For instance, Company $A$, an SME, has adopted many lean techniques, but some key personnel do not realise that what they have adopted are part of lean production. All of the company employees share the view that their objective is to be as efficient as possible in their day-to-day operation in order to increase recovery rates, as this is where value creation occurs, and how the company achieves sufficient margins to make a profit. However, again, these people do not realise that the tools and technique they are adopting originate from lean production.

The increase in product variants and frequent new product introduction seem to be the main causes of difficulty in lean implementation in remanufacturing companies. Remanufacturing companies seek standardisation, but manufacturers are simultaneously attempting to make products more innovative to meet customers' changing needs. Thus, their interests are not the same, which creates a significant challenge for remanufacturing companies, as they must be flexible and be able to respond rapidly in order to compete in the market.

The empirical evidence presented in this study shows that remanufacturers adopting lean production prefer to focus on improving the efficiency of existing processes rather than making dramatic changes to these processes. Unfortunately, the market conditions are constantly changing, and a long-term focus on existing process is not always appropriate. The need for short-term orientation is increasingly recognised, particularly for companies remanufacturing products with shortening life cycles. Thus, remanufacturers should sometimes adopt a short-term orientation in order to achieve long-term sustainability.

Another finding of this study is that not all remanufacturing case companies adopt lean manufacturing deliberately. A possible explanation for this phenomenon is that there is some alignment between the aims of lean manufacturing and remanufacturing companies. In remanufacturing companies, efficiency is the major issue, as this is where the value is created. Reclaiming value requires efficiency, since the residual value contained in cores is limited, and so the only way to maximise profitability is through efficiency. For this reason, efficiency is well embedded in remanufacturing companies. Kanban, as an example, has been used in Company $B$ for many years, but only high-level managers understand that it is a lean manufacturing principle. A similar situation was observed in Company $A$, where shop-floor employees thought that Kanban was just a simple yet powerful tool to improve efficiency. Kanban has been implemented there for years, but the employees do not consider it lean manufacturing. Company $C$ implements lean through a formal and more structured programme; all activities are well documented so that the company can easily identify which activities create value and which produce waste.

The position of remanufacturing companies in the supply chain and their market power affect how much benefit they will obtain from lean implementation. This study demonstrated that lean implementation can successfully create benefit, but not always for the remanufacturers. This was true in Company B, a contract remanufacturer for a number of OEMs. Company $B$ has successfully reduced costs through lean implementation, but its profits have not increased significantly, as the company has to share the benefit with its cores suppliers. OEMs, who are acting as cores suppliers, have the stronger bargaining power; they put pressure on Company $B$ to be even more efficient by reducing the purchase price of remanufactured products. Thus, Company $B$ was forced to share the benefits of lean implementation with the cores suppliers. Company $B$ had little choice but to meet this request from its suppliers, as cores availability is a key issue for remanufacturers. This finding confirms that of a previous study, which stated that market power determines who will reap the benefits of lean implementation (Lewis, 2000).

By contrast, in Company $A$, there was evidence that lean production has created a substantial profit increase. The remanufacturer can charge the same price to customers, and thus generate a higher profit due to the efficiency created from lean implementation.

This mixed evidence implies that the benefits of lean implementation could either diminish or increase dependent on external conditions and factors.

\section{Conclusion}

This paper has discussed the way in which remanufacturing companies adopt lean manufacturing. It was shown that although there are a number of contextual differences between remanufacturing companies and TPS, there are also similarities. Both supportive and prohibitive factors affecting lean adoption in the remanufacturing industry were 
identified. It is not claimed that the results of this study are directly applicable to other contexts and companies. Rather, this paper suggests that lean manufacturing adoption requires some adjustment based on context. One of the reasons for this is that lean is environmentally dependent on culture, industry type, power influence in the supply chain, and the buyer-supplier relationship, all of which affect the success of lean implementation.

One the most fundamental differences between remanufacturing companies and TPS is that the former are not value creators; rather, they recover value from used products. Lean manufacturing adoption in the case companies was intended to maximise the amount of value that could be reclaimed from cores. Thus, lean implementation was expected to produce a significant financial benefit in the form of increased value saving. Although there are many contextual differences between remanufacturing companies and TPS, a number of factors that are supportive of lean adoption were also found. Remanufacturing companies will benefit from these factors during lean assimilation.

The case companies follow customised routes to assimilating lean manufacturing. It was shown that a custom level of lean implementation is appropriate for creating efficient remanufacturing, as each remanufacturing company has different and unique characteristics. One of the case companies is supported by investment in R\&D, while another primarily relies on human resource. One of the findings that was consistent across all the case companies was that all companies only partially adopt lean manufacturing. Full lean implementation could be very useful for an organisation, but carries an inherent risk due to dramatic changes that would be required.

The findings of this study offer a number of managerial insights. Managers of remanufacturing companies intending to adopt lean manufacturing should aim for a balance between long-term and short-term orientation. Long-term orientation is needed because lean requires a long-term perspective; however, its implementation should not be viewed as a race to the finish line, but rather as a journey. On the other hand, the remanufacturing industry requires that all companies operating within it adjust to market need with regard to shortening product life cycles. Future research could include more cases in order to provide more generalisable results. Heavy equipment, photocopiers, and automotive engines are examples of products that are commonly remanufactured and could be studied in future research.

\section{Declaration of Conflicting Interests}

The authors declared no potential conflicts of interest with respect to the research, authorship, and/or publication of this article.

\section{Funding}

The authors received no financial support for the research, authorship, and/or publication of this article.

\section{References}

Atasu, A., Guide, V.D.R., \& Van Wassenhove, L.N. (2010). So what if remanufacturing cannibalizes my new product sales? California Management Review, 52(2), 56-76. https://doi.org/10.1525/cmr.2010.52.2.56

Bamford, D., Forrester, P., Dehe, B., \& Leese, R.G. (2015). Partial and iterative Lean implementation: two case studies. International Journal of Operations \& Production Management, 35(5), 702-727. https://doi.org/10.1108/IJOPM07-2013-0329

Behdad, S., Williams, A.S., \& Thurston, D. (2012). End-of-life decision making with uncertain product return quantity. Journal of Mechanical Design, 134(10), 100902-1-100902-6. https://doi.org/10.1115/1.4007394

Boks, C., \& Tempelman, E. (1998). Future disassembly and recyling technology: A resut of a Delphi study. Futures, 30(5), 425-442. https://doi.org/10.1016/S0016-3287(98)00046-9

Chiodo, J.D., \& Ijomah, W.L. (2012). Use of active disassembly technology to improve remanufacturing productivity: Automotive application. International Journal of Computer Integrated Manufacturing, 1-11.

https://doi.org/10.1080/0951192X.2012.667151

Comm, C.L., \& Mathaisel, D.F. (2000). A paradigm for benchmarking lean initiatives for quality improvement. Benchmarking: An International Journal, 7(2), 118-128. https://doi.org/10.1108/14635770010298584 
Cooney, R. (2002). Is "lean" a universal production system?: Batch production in the automotive industry. International Journal of Operations \& Production Management, 22(10), 1130-1147.

https://doi.org/10.1108/01443570210446342

Cox, A., \& Chicksand, D. (2005). The limits of lean management thinking: Multiple retailers and food and farming supply chains. European Management Journal, 23(6), 648-662. https://doi.org/10.1016/j.emj.2005.10.010

Cusumano, M.A. (1994). The Limits of “Lean”. MIT Sloan Management Review, 27-33.

Danese, P., Romano, P., \& Boscari, S. (2017). The transfer process of lean practices in multi-plant companies. International Journal of Operations \& Production Management, 37(4), 468-488. https://doi.org/10.1108/IJOPM-12-20140571

Easterby-Smith, M., Thorpe, R., \& Lowe, A. (2002). Management research: An introduction. London, United Kingdom: Sage Publications, Inc.

Eisenhardt, K.M. (1989). Building theories from case study research. The Academy of Management Review, 14(4), 532-550. https://doi.org/10.5465/amr.1989.4308385

Engström, T., Jonsson, D., \& Medbo, L. (1996). Production model discourse and experiences from the Swedish automotive industry. International Journal of Operations \& Production Management, 16(2), 141-158.

https://doi.org/10.1108/01443579610109893

Ferrer, G. (2003). Yield information and supplier responsiveness in remanufacturing operations. European Journal of Operational Research, 149(3), 540-556. https://doi.org/10.1016/S0377-2217(02)00454-X

Ferrer, G., \& Whybark, D.C. (2000). From garbage to goods: Successful remanufacturing systems and skills. Business Horizons, 43(6), 55-64. https://doi.org/10.1016/S0007-6813(00)80023-3

Ferrer, G., \& Whybark, D.C. (2001). Material planning for a remanufacturing facility. Production and Operations Management, 10(2), 112-124. https://doi.org/10.1111/j.1937-5956.2001.tb00073.x

Flynn, B.B., Kakibara, S.S., Schroeder, R.G., Bates, K.A., \& Flynn, E.J. (1990). Empirical research methods in operations management. Journal of Operations Management, 9(2), 250-284. https://doi.org/10.1016/02726963(90)90098-X

Franke, C., Basdere, B., Ciupek, M., \& Seliger, S. (2006). Remanufacturing of mobile phones - capacity, program and facility adaptation planning. Omega, 34, 562-570. https://doi.org/10.1016/j.omega.2005.01.016

Gehin, A., Zwolinski, P., \& Brissaud, D. (2008). A tool to implement sustainable end-of-life strategies in the product development phase. Journal of Cleaner Production, 16(5), 566-576. https://doi.org/10.1016/j.jclepro.2007.02.012

Guide, V.D.R., Souza, G.C., \& van der Laan, E. (2005). Performance of static priority rules for shared facilities in a remanufacturing shop with disassembly and reassembly. European Journal of Operational Research, 164(2), $341-353$. https://doi.org/10.1016/j.ejor.2003.12.015

Guide Jr, V., Jayaraman, V., Srivastava, R., \& Benton, W.C. (2000). Supply-chain management for recoverable manufacturing systems. Interfaces, 30(3), 125-142. https://doi.org/10.1287/inte.30.3.125.11656

Guide Jr, V., \& Li, J. (2010). The potential for cannibalization of new products sales by remanufactured products. Decision Sciences, 41(3), 547-572. https://doi.org/10.1111/j.1540-5915.2010.00280.x

Gurumurthy, A., \& Kodali, R. (2009). Application of benchmarking for assessing the lean manufacturing implementation. Benchmarking: An International Journal, 16(2), 274-308. https://doi.org/10.1108/14635770910948268

Hunter, S.L., \& Black, J.T. (2007). Lean remanufacturing: A cellular case study. Journal of Advanced Manufacturing Systems, 6(2), 129-144. https://doi.org/10.1142/S0219686707000954

Ijomah, W.L. (2009). Addressing decision making for remanufacturing operations and design-for-remanufacture. International Journal of Sustainable Engineering, 2(2), 91-102. https://doi.org/10.1080/19397030902953080 
Ijomah, W.L., \& Chiodo, J.D. (2010). Application of active disassembly to extend profitable remanufacturing in small electrical and electronic products. International Journal of Sustainable Engineering, 3(4), 246-257.

https://doi.org/10.1080/19397038.2010.511298

Ilgin, M.A., \& Gupta, S.M. (2011). Performance improvement potential of sensor embedded products in environmental supply chains. Resources, Conservation and Recycling, 55(6), 580-592.

https://doi.org/10.1016/j.resconrec.2010.05.001

Inderfurth, K., Vogelgesang, S., \& Langella, I.M. (2015). How yield process misspecification affects the solution of disassemble-to-order problems. International Journal of Production Economics, 169, 56-67.

https://doi.org/10.1016/j.ijpe.2015.07.016

Ketzenberg, M.E., Laan, E., \& Teunter, R.H. (2009). Value of information in closed loop supply chains. Production and Operations Management, 15(3), 393-406. https://doi.org/10.1111/j.1937-5956.2006.tb00253.x

Ketzenberg, M.E., Souza, G.C., \& Guide, V.J. (2003). Mixed assembly and disassembly operations for remanufacturing. Production and Operations Management, 12(3), 320-335. https://doi.org/10.1111/j.19375956.2003.tb00206.x

Lee, B.H., \& Jo, H.J. (2007). The mutation of the Toyota production system: adapting the TPS at Hyundai Motor Company. International Journal of Production Research, 45(16), 3665-3679. https://doi.org/10.1080/00207540701223493

Lewis, M.A. (2000). Lean production and sustainable competitive advantage. International Journal of Operations and Production Management, 20(8), 959-978. https://doi.org/10.1108/01443570010332971

Liker, J.K., \& Meier, D. (2006). The Toyota fieldbook: A practical guide for implementing Toyota's 4Ps. New York, United States: McGraw Hill.

Lind, S., Olsson, D., \& Sundin, E. (2014). Exploring inter-organizational relationships in automotive component remanufacturing. Journal of Remanufacturing, 4(1), 1-14. https://doi.org/10.1186/2210-4690-4-5

Lund, R.T. (1984). Remanufacturing: the experience of the USA and implications for the developing countries. Washington, D.C.: World Bank.

Maxwell, J.A. (2009). Designing a qualitative study. In Bickman, L., \& Rog, D.J. (Eds.), The Sage handbook of applied social research methods (2nd ed., 214-253). Thousand Oak, CA. https://doi.org/10.4135/9781483348858.n7

Meredith, J. (1998). Building operations management theory through case and field research. Journal of Operations Management, 16, 441-454. https://doi.org/10.1016/S0272-6963(98)00023-0

Oliver, N., \& Hunter, G. (1998). The financial impact of "Japanese" manufacturing methods. Manufacturing in transition (Chapter 5). Routledge \& Kegan Paul, London.

Ostlin, J., \& Ekholm, H. (2007). Lean production principles in remanufacturing a case study at a toner cartridge remanufacturer. In Electronics \& the Environment, Proceedings of the 2007 IEEE International Symposium on IEEE (216-221). https://doi.org/10.1109/ISEE.2007.369397

Östlin, J., Sundin, E., \& Björkman, M. (2008). Importance of closed-loop supply chain relationships for product remanufacturing. International Journal of Production Economics, 115(2), 336-348.

https://doi.org/10.1016/j.ijpe.2008.02.020

Papadopoulou, T.C., \& Özbayrak, M. (2005). Leanness: experiences from the journey to date. Journal of Manufacturing Technology Management, 16(7), 784-807. https://doi.org/10.1108/17410380510626196

Piercy, N., \& Rich, N. (2015). The relationship between lean operations and sustainable operations. International Journal of Operations \& Production Management, 35(2), 282-315. https://doi.org/10.1108/IJOPM-03-2014-0143

Robinson, A.G. (2009). The role of front-line ideas in lean performance improvement. Quality Management Journal, 16(4), 27-40. https://doi.org/10.1080/10686967.2009.11918248 
Rymaszewska, A.D. (2014). The challenges of lean manufacturing implementation in SMEs. Benchmarking: An International Journal, 21(6), 987-1002. https://doi.org/10.1108/BIJ-10-2012-0065

Saavedra, Y.M.B., Barquet, A.P.B., Rozenfeld, H., Forcellini, F.A., \& Ometto, A.R. (2013). Remanufacturing in Brazil: case studies on the automotive sector. Journal of Cleaner Production, 53, 267-276.

https://doi.org/10.1016/j.jclepro.2013.03.038

Saunders, M., Mann, R., \& Smith, R. (2007). Benchmarking strategy deployment practices. Benchmarking: An International Journal, 14(5), 609-623. https:// doi.org/10.1108/14635770710819281

Sitkin, S.B. (1992). Learning through failure: the strategy ofsmall losses. Research in Organizational Behavior, 14, $231-266$.

Sundin, E., Elo, K., \& Mien-Lee, H. (2012). Design for automatic end of life processes. Assembly Automation, 32(4), 389-398. https://doi.org/10.1108/01445151211262447

Tang, O., Grubbstrom, R.W., \& Zanoni, S. (2007). Planned lead time determination in a make-to-order remanufacturing system. International Journal of Production Economics, 108(1-2), 426-435.

https://doi.org/10.1016/j.ijpe.2006.12.034

Teunter, R.H. \& Flapper, S.D.P. (2011). Optimal core acquisition and remanufacturing policies under uncertain core quality fractions. European Journal of Operational Research, 210(2), 241-248. https://doi.org/10.1016/j.ejor.2010.06.015

Vinodh, S., Nachiappan, N., \& Kumar, R.P. (2012). Sustainability through disassembly modeling, planning, and leveling: A case study. Clean Technology and Environmetal Policy, 14(1), 55-67. https://doi.org/10.1007/s10098-011-03615

Westkamper, E., Feldmann, K., Reinhart, G., \& Seliger, G. (1999). Keynote papers: Integrated development of assembly and disassembly. Annals of the CIRP, 48(2), 557-565. https://doi.org/10.1016/S0007-8506(07)63234-X

Womack, J.P., Jones, D.T., Roos, D., \& Carpenter, D.S. (1990). The machine that changed the world: How lean production revolutionised the global car wars. Sydney, Australia: Simon \& Schuster.

Yin, R.K. (2009). Case study research: Design and methods (4th Ed.). London, United Kingdom: Sage Publications, Inc.

Zikopoulos, C., \& Tagaras, G. (2008). On the attractiveness of sorting before disassembly in remanufacturing. IIE Transactions, 40(3), 313-323. https://doi.org/10.1080/07408170701488078

Journal of Industrial Engineering and Management, 2018 (www.jiem.org)

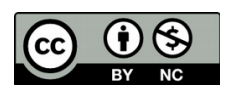

Article's contents are provided on an Attribution-Non Commercial 4.0 Creative commons International License. Readers are allowed to copy, distribute and communicate article's contents, provided the author's and Journal of Industrial Engineering and Management's names are included. It must not be used for commercial purposes. To see the complete license contents, please visit https://creativecommons.org/licenses/by-nc/4.0/. 